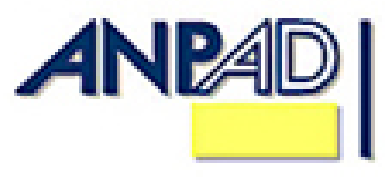
Disponível em
http://www.anpad.org.br/rac
RAC, Rio de Janeiro, v. 18, n. 5,
pp. 710-718, Set./Out. 2014
http://dx.doi.org/10.1590/1982-7849rac201410671
$($ co) EY-No

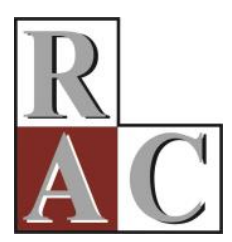

Documentos e Debates:

\title{
Réplica 1 - Clássicos \& Formação em Administração: O Que, Quando, Para Que
}

\author{
Classics and Training in Management: What, When and Why
}

Janette Brunstein

E:mail: janette@mackenzie.br

Universidade Presbiteriana Mackenzie

Rua Consolação, 896, sala 76, Consolação, 01302-907, São Paulo, SP, Brasil.

Pedro Jaime

E-mail: pedrojaime@uol.com.br Centro Universitário da Fundação Educacional Inaciana Rua Tamandaré, 688, Liberdade, 01525-000, São Paulo, SP, Brasil. 


\section{Introdução}

Ao proporem o presente debate, os autores fazem reflexões importantes sobre a presença dos clássicos na formação dos administradores, reflexões estas com as quais concordamos no essencial. Porém partimos do pressuposto de que um bom artigo, seja lá o que isso signifique, é aquele que não deixa o leitor inerte, gerando reações. Sentimos isso em relação a este texto. Na medida em que avançávamos na leitura, éramos tomados pelo desejo de dizer algo, de participar da discussão para a qual eles nos convidavam, a nós, que fazemos parte da comunidade científica de Administração. Assim, nas linhas que seguem, apresentamos uma contribuição em dois momentos: primeiramente, recuperamos os argumentos centrais desenvolvidos pelos autores; posteriormente, lançamos algumas provocações, com a consciência de que não era necessariamente a intenção deles explorar as trilhas que iremos sugerir, por isso falamos em provocações, e não em críticas.

\section{Síntese}

De acordo com a nossa leitura, é possível identificar duas intenções principais dos autores ao escreverem o texto. A primeira é refletir sobre a definição de clássico, a sua construção social e o contexto histórico em que esse processo se dá. Concomitante a este propósito, evidencia-se a importância da leitura dos clássicos. A segunda intenção é discutir o lugar dos clássicos no ensino e na pesquisa em Administração.

Quanto à primeira intenção, a despeito de sinalizarem para a questão da definição em uma das seções do artigo, os autores remarcam reiteradamente que não pretendem definir o que é um clássico. Eles destacam que possuem até mesmo reservas quanto ao valor de tal definição. Ressaltam, no entanto, que várias áreas do conhecimento possuem os seus clássicos e que isso lhes garante legitimidade. Legitimidade, aliás, que, segundo os autores, não é apenas do campo em si, mas dos docentes e pesquisadores que o formam, uma vez os clássicos lhes atribuem status, apontam para o intelectual que se é ou se pretende ser. Dessa perspectiva, o professor-pesquisador que conhece bem os clássicos da sua área ocupa um lugar diferenciado em seu campo de estudos.

E se essas áreas do conhecimento, e também os pesquisadores que as constituem, possuem clássicos é porque algumas obras foram assim construídas. Quanto a esse aspecto, os autores chamam a atenção para o fato de que, em qualquer campo científico, os clássicos não são dados; eles são socialmente produzidos. E esse processo de produção social dos clássicos é tributário do contexto histórico e atravessado por tensões e conflitos. Os clássicos são definidos nos encontros intersubjetivos que marcam uma comunidade científica. Desses encontros fazem parte os jogos políticos. Assim, o que os autores buscam não é exatamente definir o clássico, mas evidenciar que cada campo elege os seus clássicos de maneira dinâmica, sendo que autores desprezados no passado podem ser recuperados em razão de mudanças no contex to histórico e das alterações na balança do poder dentro do campo.

No que diz respeito à importância da leitura dos clássicos, os autores a ressaltam a partir de alguns argumentos. Um deles se refere ao potencial reflexivo dos clássicos. Eles têm a capacidade de empoderar o leitor, fazê-lo se constituir enquanto ser autônomo na maneira de pensar e compreender o mundo. Consequentemente, são geradores de reflexões profundas, capazes de suscitar o senso crítico, o alargamento da visão. A defesa dos clássicos se dá também pela possibilidade de resistência à era de industrialização do trabalho intelectual na qual vivemos, reconhecida por sua ênfase no quantitativo, isto é, pelo volume de produção de papers anuais. Advogar o valor dos clássicos seria igualmente resistir à força do mercado editorial, que impõe livros-texto facilmente consumíveis. A leitura de autores clássicos seria então uma via privilegiada para uma formação intelectual consistente, em contraste com a literatura mais técnica, tida como superficial. Finalmente, é atribuída aos clássicos a capacidade de educação civilizatória, que se refere, em última instância, à condição humana, independente do tempo 
histórico no qual foram produzidas as obras. Haveria, assim, uma função ritual desempenhada pelos clássicos, que levariam o leitor à sensação de pertença a uma história comum.

Quanto ao que designamos como a segunda intenção principal dos autores, a ênfase recai sobre a importância dos clássicos no ensino e na pesquisa em Administração. $\mathrm{Na}$ visão dos mesmos, essa importância é tanto maior em razão de o fazer científico desta área ser marcado pela predominância do paradigma positivista, que acabou induzindo ao afastamento dos clássicos. Como reflexo, assiste-se, muitas vezes, a uma desvalorização das grandes narrativas e, em oposição, à valorização de conhecimentos parcializados e restritos a resultados de pesquisas. A formação do administrador enfatiza, assim, aspectos de natureza técnico-metodológica em detrimento da construção de bases epistemológicas consistentes, capazes de levar os alunos e os pesquisadores a um desenvolvimento intelectual contínuo ao longo dos anos. Ademais, a importância dos clássicos na formação em Administração residiria também na contribuição que eles podem dar ao trânsito interdisciplinar, capaz de provocar reflexões profundas na área. Isto fortaleceria a Administração enquanto campo de conhecimento autônomo, num processo similar ao que ocorreu com a Psicologia e a Sociologia.

Feito esse breve resgate das ideias centrais do texto, apresentamos, a seguir, as provocações que deixamos para alimentar a reflexão dos autores (e da comunidade científica da Administração em geral). Para tanto procuramos ampliar a indagação lançada pelos autores sobre os clássicos no ensino e na pesquisa em Administração. À pergunta por quê??, acrescentamos as interrogações: o quê?; quando?; para quê?.

\section{O Quê? Ou em Que Fontes Buscar Clássicos}

Um primeiro bloco de questões que o texto dos autores nos suscitou diz respeito a o que estamos falando exatamente quando nos referimos a clássicos. Nesse caso, gostaríamos de fazer três provocações.

\section{Definição de clássico: superando o suposto universalismo ocidental}

A primeira provocação diz respeito ao horizonte intelectual no qual se definem os clássicos que devem ser lidos no ensino e na pesquisa em Administração. Se bem entendemos os seus argumentos, quando defendem essa leitura, os autores estão pensando em obras das Ciências Sociais e das Humanidades. E a referência a essas obras se dá dentro do horizonte intelectual que podemos definir como sendo aquele do mundo ocidental. Pensamos aqui no Ocidente em sua conotação geopolítica e, quanto a isso, gostaríamos de fazer uma ressalva antes de colocar a nossa provocação. Muitos jornalistas e pesquisadores incluem o Brasil em suas considerações sobre o Ocidente, especialmente quando estão pensando esse Ocidente em contraste com um Oriente imaginado (Said, 2007), por exemplo, ao falarem da Primavera Árabe. Todavia não é assim que nos veem os países centrais. Na Europa ocidental e nos Estados Unidos, não somos enquadrados na categoria Ocidente, mas sim na rubrica América Latina. Corroborando essa forma de os países centrais nos situarem no mundo, recentemente, uma aluna concluinte de Administração que trabalha em uma multinacional disse a um de nós que a companhia segmenta seus mercados em: Europa, América do Norte (leia-se Estados Unidos e Canadá) e RTW, isto é, Rest of the World. Pois bem, é dentro desse quadro de referência que queremos chamar a atenção para o fato de que, quando os autores falam de uma educação civilizatória associada à leitura dos clássicos, que levariam o leitor à sensação de pertencimento a uma história comum, parece-nos que eles estão se referindo, sobretudo, aos clássicos das Ciências Sociais e das Humanidades produzidos pelo mundo Ocidental. Todavia, está em curso um amplo debate no campo intelectual, com rebatimentos inclusive nas Ciências Sociais, sobre a necessidade de um pensamento pós-colonial ou mesmo descolonizador. Nesse sentido, novos clássicos são reivindicados. Referindo-se à formação em Antropologia, por exemplo, José Jorge de Carvalho afirmou, recentemente, a necessidade de se expandir o cânone teórico visando formar o que chamou de um espaço multiepistêmico. Sugeriu, então, que os alunos estudassem, desde o primeiro semestre da graduação, junto com os europeus e os brasileiros brancos, os cientistas 
Sociais negros (Abdias do Nascimento, Guerreiro Ramos, Lélia Gonzalez, Beatriz Nascimento, entre outros) e os intelectuais indígenas. Propôs igualmente incorporar na formação dos antropólogos os cientistas sociais e os intelectuais dos demais países da América Latina e do Caribe, entre os quais: Orlando Fals Borda, Aníbal Quijano, Rigoberta Menchú, Fernando Ortiz, C.L.R. James, Eric Williams, Aimé Césaire, Frantz Fanon, e até mesmo os ensaístas notáveis, como Octavio Paz, José Lezama Lima e José Carlos Mariátegui. Recomendou ainda a recuperação da tradição intelectual africana negada: Nkrumah, Cheik Anta Diop, Amadou Hampatê Bá, Kizerbo, Senghor, que deveria ter sido fundante desde os anos sessenta do século passado, contexto de descolonização dos países africanos (Lima \& Jaime, 2010). Não se trata, nesses comentários, de aprofundar a discussão sobre a importância do pensamento pós-colonial. Destacamos, contudo, que, daqui de onde vemos as coisas, caberia perguntar: não precisamos ampliar o horizonte intelectual a partir do qual definimos os clássicos que devem orientar a formação para o ensino e a pesquisa em Administração? Ao fazermos isso não estaríamos contribuindo para descolonizar o espaço mental dos administradores brasileiros, formados quase que exclusivamente a partir da mimetização da produção teórica estado-unidense?

\section{Desfazendo a oposição entre clássicos e literatura técnica}

A segunda provocação remete a uma demarcação de clássico em contraste com a literatura parcializada e restrita a resultados de pesquisas. A nosso ver, no afã de situar a importância da leitura dos clássicos, os autores correm o risco de estabelecer o que consideramos uma falsa dicotomia entre os textos identificados como canônicos e aqueles tidos como mais pontuais.

Há uma tendência em parte da comunidade científica de se entender a leitura mais técnica como pouco inspiradora, ou até mesmo incapaz de gerar reflexões relevantes. No caso do campo da Administração essa tendência não surgiu por acaso. Ela nos parece ser uma reação ao utilitarismo que marcou a produção científica nesta área em sua origem, que reduziu os profissionais à capacidade de definir ou executar metas específicas, levando a um empobrecimento da formação do administrador, ranço taylorista que carregamos até hoje. E muitos livros e artigos resultantes de pesquisas cumpriram (e ainda cumprem) este papel domesticador e, assim, convidam mais à reprodução do conhecimento do que à reflexão contextual.

A questão é que, do nosso ponto de vista, tanto a leitura de clássicos, das grandes narrativas, como as leituras mais técnicas podem estar, ou não, a serviço da inteligência humana, da nossa capacidade de pensar, compreender e, como indica Paulo Freire (1996), fazer-nos intervir no mundo. Levando isso em conta, indagamos: acaso um artigo, fruto de pesquisa empírica, quando bem-elaborado, respeitando os rigores metodológicos e empreendendo reflexões consistentes e inovadoras, não poderia se constituir num texto clássico num campo do saber? Não se trata aqui de responder a essa pergunta. Contudo, nos questionamos, é pertinente demarcar o clássico por sua oposição à literatura mais parcial e metodologicamente estruturada.

\section{Alargando a concepção de clássico}

Stanley Fish (1992), em seu clássico artigo: Is There a Text in this Class?, assinala que o significado que damos a um texto supõe uma comunidade interpretativa. Isto é, os rótulos identificatórios que atribuímos a uma obra ou autor, se o criticamos ou o elogiamos, se o colocamos na categoria de clássico ou não, só o fazemos dentro de um universo de discurso, de marcas de designação e formas de argumentação que foram sendo construídas ao longo do tempo. Nenhuma interpretação do que é ou deixa de ser um clássico, se é bom ou ruim, faz-se à deriva do sistema (contexto, situação ou comunidade interpretativa) que os julga.

Assim, quando os autores circunscrevem o debate sobre os clássicos na Administração enfatizando os cânones das Ciências Sociais e Humanidades, observamos esta força da comunidade interpretativa. Para deixar mais clara esta ideia, poderíamos perguntar, em um exercício de reflexão: não caberia alargarmos a concepção de clássicos tal qual debatida no texto? 
Eagleton (1983), um autor que discute teoria literária, questiona se determinados slogans e refrãos de torcidas de futebol, manchetes de jornal, anúncios publicitários não poderiam ser classificados como literatura. De forma análoga, perguntamos, por exemplo, se os quadrinhos de Scott Adams sobre as desventuras de Dilbert no mundo empresarial não poderiam ser compreendidos como clássicos também. Arguimos isso, sobretudo, porque estamos diante de uma nova geração cuja subjetividade é fortemente marcada pelo audiovisual, uma vez que vivemos em uma sociedade centrada na mídia. Nesse contexto, cabe interrogar: um conjunto de vídeos do YouTube, filmes, muitos deles usados de forma recorrente nas salas de aula das escolas de negócios não poderiam ser considerados clássicos também? Ao levantarmos essas indagações, corremos o risco de propor uma ideia de clássico demasiadamente fluída e, portanto, improfícua, já que qualquer coisa poderia ser um clássico. Temos consciência desse risco, mas acreditamos que é necessário corrê-lo e propor que o debate sobre os clássicos na formação em Administração enfrente essa complexa questão.

\section{Quando? Ou sobre as Condições Concretas de Leitura dos Clássicos}

Um segundo bloco de provocações que gostaríamos de fazer aos autores (e a comunidade científica de Administração, em geral) diz respeito a quando os clássicos devem entrar na formação dos administradores, pergunta capciosa que nos leva a refletir sobre as condições concretas de leitura dos clássicos na formação em Administração.

Se o julgamento de valor de um clássico se dá, sobretudo, por seu poder de induzir reflexão profunda, como pretendem os autores, temos aqui um aspecto importante a ser considerado. As reações ao texto, sua significância, dependem da experiência sentida pelo leitor no contato com a obra, da sua reação particular, enfim, da sua singularidade imaginativa. A relevância do clássico nesta lógica se daria pelo efeito que pode ser capaz de produzir: o estranhamento, a desfamiliarização, ou seja, ele desautomatizaria o olhar (Eagleton, 1983).

Dessa forma, se o personagem central é o leitor dos clássicos, então, ficamos nos perguntando: (a) Quem é este sujeito que lê (ou que deveria ler) os clássicos na formação em Administração? (b) Em que condições lê os clássicos nesse processo de formação? A nossa reação, neste caso, dá-se em forma de preocupação, inquietude. Compartilhamos com os autores a importância dos clássicos no ensino e na pesquisa em Administração. E qual a razão para a preocupação, então? É que nos interrogamos se o atual contexto sócio-histórico no qual se dá essa formação favorece a boa leitura dos clássicos, com tudo o que ela convida (reflexão crítica, exercício de imaginação, etc.). Pensamos aqui em dois tipos de leitores: o aluno de graduação e o de pós-graduação, sobretudo nos níveis de mestrado e doutorado.

Com relação ao aluno da graduação, fizemos a seguinte reflexão. A grande maioria dos alunos de Administração das diversas IES existentes em nosso país que oferecem esse curso se defronta com o seguinte desafio: como conciliar o curso universitário com a necessidade de trabalhar, sem falar nas demais exigências de formação para o mercado de trabalho (cursos de línguas, etc.) e nas variadas demandas da vida social e familiar. Trabalhando em uma IES privada com reputação nacional e voltada para um público de classe média-alta, deparamo-nos constantemente com queixas dos alunos referentes à sobrecarga de leituras e avaliações. Muitos deles reconhecem que em diversas oportunidades estudaram para os exames a partir dos apontamentos tomados nos cadernos (de papel ou eletrônicos) e que a leitura desses apontamentos, ou mesmo de capítulos dos livros indicados pelos professores, acontece no transporte coletivo a caminho da universidade.

São várias as razões de ordem socioeconômica que ajudam a construir esse quadro e não é o caso de retomá-las aqui. O fato é que é esta a realidade concreta desse sujeito em formação. Tendo isso em vista, perguntamo-nos: trata-se de uma condição favorável à leitura dos clássicos? Ou até mesmo de uma condição em que é possível retirar dessa leitura o que os clássicos podem oferecer? Também não pretendemos responder a essas perguntas. A nossa intenção é tão somente a de lançar provocações. Adiantamos, todavia, que não acreditamos que essa preocupação que externamos deva levar a uma 
paralisia, algo como: desistamos então de incentivar a leitura dos clássicos na formação de administradores em nível de graduação. Não se trata disso. Tal como os autores, acreditamos que a leitura dos clássicos tem um potencial de questionamento e, portanto, de transformação da realidade. Mas, para lembrar mais uma vez Paulo Freire (1996), um clássico da Educação, pensar o processo de ensino-aprendizagem e seu potencial transformador não pode prescindir de uma reflexão sobre as condições concretas de vida do educando.

Seja como for, parece-nos que ao escreverem o seu texto os autores estavam pensando, sobretudo, no aluno de pós-graduação em Administração, em nível de mestrado e doutorado. Eles têm um papel importante na produção da pesquisa nesse campo. Quanto a esse público, a nossa preocupação possui algumas nuanças, mas é basicamente a mesma. As indagações que ficamos nos fazendo foram: (a) Face as atuais exigências em termos de prazo para a conclusão dos cursos de stricto sensu, os estudantes têm a possibilidade de escapar das leituras focadas em seus objetos de estudo para se dedicarem à leitura dos clássicos, com a necessária abertura para aproveitar as possibilidades que esta leitura permite? (b) $\mathrm{O}$ fato de boa parte dos alunos desenvolverem seus mestrados/doutorados concomitantemente ao trabalho, seja como docente em IES, seja como profissionais de empresas, não coloca ainda mais desafios a uma leitura qualificada dos clássicos? Não pretendemos igualmente responder a essas perguntas. Visamos, apenas, sinalizar para uma questão a ser considerada no debate. Nesse sentido, deixamos aqui o relato, em forma de anedota, de uma situação vivida por um de nós. O contexto: aula sobre cultura brasileira ministrada numa disciplina de um programa de pós-graduação em Administração. Os alunos ouviam atentamente um renomado cientista social brasileiro abordar o tema. Este recuperou uma série de ideias de clássicos do pensamento social brasileiro: Sergio Buarque, Caio Prado, Gilberto Freyre, Florestan Fernandes, entre outros. Sua intenção era visivelmente a de evidenciar a centralidade das obras produzidas por estes autores para o entendimento da cultura brasileira. Todavia, num dado momento, deixou para os presentes a seguinte sugestão: "Não leiam esses autores agora não. Cuidem de suas dissertações e teses. Essas são leituras para vocês fazerem com tempo, após a conclusão dos seus trabalhos" (C. G., Mota, comunicação pessoal, 22 de novembro de 2010). Se tomarmos a formação de professores e pesquisadores em Administração em sentido estrito, como algo que se dá ao longo da realização de cursos de mestrado e doutorado, podemos dizer que aquele cientista social estava desencorajando a presença dos clássicos nesse processo. Mesmo sabendo que a formação de docentes e investigadores se faz ao longo da trajetória profissional, podemos tomar a interpelação do professor como uma reflexão não apenas sobre o porquê de ler os clássicos na formação em Administração, mas também quando se lançar nessa empreitada.

Mas o debate sobre as condições concretas da presença dos clássicos na formação em Administração ainda suscita outra reflexão. Recorrendo novamente ao argumento de Stanley Fish (1992), sobre a comunidade interpretativa, sugerimos que a discussão a esse respeito leve em conta dois outros aspectos. De um lado, a inevitável imbricação da leitura dos clássicos dentro das relações dialéticas entre alunos, docentes, orientadores e pesquisadores. De outro lado, as estruturas curriculares, organizacionais e institucionais nas quais estas relações se dão e por onde os textos circulam, são valorizados ou deixam de sê-lo. Pensamos aqui na seguinte indagação: qual o espaço para um debate aprofundado sobre Marx em Instituições de Ensino Superior (IES) confessionais ou em uma business school? Não sugerimos de antemão que esse espaço inexista, mas afirmamos que há uma questão institucional aqui, que não podemos nos furtar a enfrentar. Quem define o currículo, os autores, o tempo de bacharelado, os espaços para leituras? Quem determina quais são os clássicos e quando (e quanto) devemos nos ater a eles neste contexto de formação industrializada e massificada em que vivemos atualmente e em razão dos projetos político pedagógicos de cada IES?

Talvez estas sejam às questões mais importantes sobre as quais devamos nos debruçar. Isso porque, a priori, dificilmente encontraremos argumentos de desvalorização sumária dos clássicos, sejam eles quais forem. A discordância, então, fica mais por conta do quando e como se pode fazer uso desses textos, e de quem são os cânones. 


\section{Para Quê? Ou Quais Usos dos Clássicos}

Um terceiro bloco de provocações que gostaríamos de fazer se refere às razões que levam à leitura dos clássicos no ensino e na pesquisa em Administração. Nesse caso, também, dividimos nossas provocações em subseções.

\section{O uso dos clássicos como marca de distinção no campo acadêmico}

A que se presta a leitura das obras consideradas clássicas na formação em Administração? Será que elas estão sempre a serviço da formação de um profissional mais crítico e capaz de realizar reflexões originais? Evidentemente, não negamos essa possibilidade, mas queremos sugerir que as coisas podem se passar de outra forma. Adaptando uma observação de Eagleton (1983), diríamos que se um aluno de graduação, mestrado ou doutorado cita, em sala de aula, a mais-valia de Marx, o pan-óptico de Foucault, ou a ação comunicativa de Habermas, isso nos leva a crer que estamos em presença de um acadêmico, de um estudioso. Isso porque haveria, nas referências que ele mobiliza, algo que difere sobremaneira da linguagem cotidiana. Tal afastamento do falar comum, em princípio, permitiria que os estudantes de Administração pensassem e vivenciassem a realidade organizacional de forma mais crítica e original. Mas nem sempre é isso o que acontece. Por acaso o uso feito por alguns estudantes (ou mesmo pesquisadores e docentes) dos clássicos não pode representar um verniz de ilustração, sem remeter a reflexões mais profundas dos indivíduos que recorrem a eles?

Essa é uma pergunta espinhosa e não caberia respondê-la peremptoriamente, mas ressaltamos que foram diversas as vezes que nos defrontamos, em nossas trajetórias profissionais, com verdadeiras performances em que os clássicos das Ciências Sociais e das Humanidades apareceram no falar dos membros da comunidade científica de Administração (ou são apressada e ingenuamente desconstruídos por eles) como mero mecanismo de distinção. Uma distinção que remete à presença de um discurso competente (Chauí, 2011). O que nos espanta nessas ocasiões é que, por vezes, o recurso aos clássicos está associado a posturas intelectuais e políticas conservadoras, bem distante do sujeito crítico e criativo que os clássicos potencialmente ajudam a formar.

Enfim, a pergunta para que coloca ênfase no sentido que os clássicos vêm assumindo na formação em Administração, o que eles fazem os administradores pensarem, quererem do trabalho e das organizações, para si e para as próximas gerações?

\section{Dos clássicos na Administração aos clássicos da Administração}

Enfocar certos usos menos indutores de uma reflexão crítica e original que estudantes ou docentes de Administração fazem dos clássicos, da função que eles desempenham em suas falas, nos remete a outro ponto importante levantado pelos autores. Para eles, conforme já afirmamos, os clássicos desempenham um papel bastante relevante na constituição de um campo científico, uma vez que lhe garante legitimidade. Partindo dessa premissa, com a qual concordamos, queremos sugerir que o debate sobre clássicos e formação de administradores incorpore não apenas os clássicos na Administração, mas também os clássicos da Administração.

Paul Adler (2009) dá o seguinte subtítulo à introdução escrita para apresentar a coletânea Sociology and Organization Studies: uma ciência social que esquece os seus fundadores está perdida. Falando sobre o campo interdisciplinar dos estudos organizacionais, ele parte da seguinte constatação: este campo está, hoje, institucionalizado tanto nos departamentos de Sociologia quanto nas escolas de Administração, todavia ao longo desse processo de institucionalização perdeu contato com os seus fundadores. Na visão de Adler, para alguns, isto significaria um sinal, positivo, de que este campo atingiu a maturidade. Ele lembra, quanto a isso, uma citação de Alfred North Whitehead, segundo o qual: uma ciência que hesita a esquecer de seus fundadores está perdida. Adler ressalta então que, ao falar isso, Whitehead estava se referindo às Ciências Naturais e, então, argumenta que as Ciências Sociais são bem diferentes, pois nelas os clássicos continuam a desempenhar um papel crucial. Advoga 
então que, sem minimizar as contribuições de autores mais recentes, a proposta do livro que ele apresenta é inverter a advertência de Whitehead.

Partimos dessa sugestão de Paul Adler para apresentar esta nossa reação ao texto dos autores. E se problematizássemos não apenas a leitura dos clássicos das Ciências Sociais e das Humanidades no ensino e na pesquisa em Administração, mas também a leitura dos clássicos da Administração na formação para a docência e a investigação nesta área? Ressaltamos, logo de saída, que, ao utilizarmos a conjunção também nesta interrogação, queremos sugerir que se trata de algo complementar ao exercício proposto pelos autores. Seja como for, colocar a indagação nesses termos nos leva a novas perguntas, entre as quais: A Administração possui clássicos? Quem são eles? Como são definidos? São imprescindíveis à formação nessa área do conhecimento? Não temos pretensões de responder a estas questões. Temos consciência da complexidade que elas encerram e, quanto a isso, fazemos eco a um argumento lançado pelos autores sobre a construção dos clássicos: eles só podem ser definidos no debate aberto, e atravessado por conflitos, entre os membros da comunidade científica. Mas ao recorremos à máxima de Adler, supramencionada, sugerimos que parece ter acontecido com a Administração algo que ele sinaliza para o campo interdisciplinar dos estudos organizacionais: a institucionalização levou à perda de contato com os fundadores. Apenas adaptaríamos essa constatação, substituindo fundadores por clássicos.

O leitor pode considerar que essa advertência é exagerada para a Administração. Acaso os alunos de graduação e pós-graduação não cursam disciplinas de Teoria Geral da Administração, Teoria das Organizações e correlatas e nelas não visitam os clássicos do campo? A resposta a essa pergunta é positiva. Sim, eles cursam essas disciplinas e nelas, de alguma forma, visitam os clássicos da área. Mas, nesses momentos, são interpelados a defrontarem-se com os clássicos da Administração nos termos propostos pelos autores para o encontro com os clássicos das Ciências Sociais e das Humanidades? Nossa resposta para essa pergunta é negativa, visto que consideramos que esse encontro se dá, sobretudo, em segunda mão, pela via de compiladores, e sem o devido aprofundamento, e por isso a deixamos como provocação.

\section{Considerações Finais}

Há uma última consideração que gostaríamos de fazer em nossos comentários ao texto dos autores. Ela diz respeito à provocação que fizemos acima a propósito dos clássicos da Administração. Em uma área tão afeita a modismos como a Administração, não haveria uma tendência de se apressar a formação dos clássicos, enxergando como tal qualquer novo livro que desponte no mercado acadêmico ou extra-acadêmico? O texto dos autores, ao refletir sobre a construção social dos clássicos das Ciências Sociais e das Humanidades, oferece-nos antídotos a esse a que consideramos um risco concreto. Também quanto a isso, optamos por deixar o questionamento em aberto, suscitando reações dos leitores. Sugerimos, entretanto, uma trilha de reflexão. Uma trilha traçada também em forma de anedota, tomada desta vez de um clássico da literatura. Numa entrevista a um canal de televisão, por ocasião do lançamento do seu livro O Romance d'a Pedra do Reino, Ariano Suassuna disse distinguir sucesso de êxito. Sucesso, afirmou o escritor pernambucano, é algo que diversas bandas de rock contemporâneas conseguem com maior ou menor dificuldade, sucedendo-se umas as outras. Mas êxito, argumentou ele, é algo completamente diferente. Êxito, ressaltou com um toque de ironia, conseguiu Euclides da Cunha, cujo livro Os sertões, publicado pela primeira vez em 1902, recebe até os dias de hoje novas edições. Para alguns, talvez, essa contraposição proposta por Suassuna não esteja adequada aqui, sendo mais apropriado ampliarmos, com Eagleton (1983), as fontes nas quais são buscados os clássicos. Para outros, é possível ela seja altamente pertinente, dado a inflação de astros pop no campo da Administração. Não consideramos, entretanto, as colocações do Dom Quixote brasileiro e do crítico cultural inglês como excludentes, mesmo se podem nos convidar a incorporar paradoxos. Afirmamos isso por que se Eagleton propõe um alargamento do que seja um clássico da literatura, remetendo o seu leitor para o jornalismo e a publicidade, sua proposição não prescinde de uma discussão sobre a qualidade percebida pela audiência para que alguma produção seja tida como clássico. Nesse sentido, e voltando a enfocar as 
obras clássicas produzidas como livros, objeto da reflexão dos autores cujo texto comentamos, consideramos que Eagleton se aproxima de Suassuna e ambos alertam-nos para os cuidados que nós, da comunidade científica da Administração, devemos ter se desejamos retomar o debate sempre aberto sobre os clássicos desse campo do saber.

\section{Referências}

Adler, P. (2009). Introduction: a social science which forgets its founders is lost. In P. Adler (Ed.), The Oxford handbook of sociology and organization studies: classical foundations (pp. 3-19). Oxford: Oxford University Press.

Chauí, M. (2011). Cultura e democracia: o discurso competente e outras falas. São Paulo: Cortez.

Eagleton, T. (1983). Teoria da literatura. São Paulo: Martins Fontes.

Fish, S. (1992). Is there a text in this class? Alfa Revista de Linguística, 36, 189-206. Recuperado de http://seer.fclar.unesp.br/alfa/\%20article/view/3919/3600

Freire, P. (1996). Pedagogia da autonomia. São Paulo: Paz e Terra.

Lima, A., \& Jaime, P. (2010). Entrevista com o professor José Jorge de Carvalho [Versão eletrômica]. Cadernos de Campo, (19), 207-227.

Said, E. (2007). Orientalismo. São Paulo: Companhia das Letras. 